\title{
Thrombus in Transit Causing Acute Massive Pulmonary Emboli Treated Successfully with Reteplase Administration
}

\author{
Muhammet Bugra Karaaslan, Aziz Inan Celik', Caglar Emre Cagliyan, Mesut Demir \\ Department of Cardiology, Medical Faculty, Cukurova University, Adana, Turkey, ${ }^{1}$ Department of Cardiology, Bayburt State Hospital, Bayburt, Turkey
}

\section{Abstract}

Acute pulmonary thromboembolism (PTE) is a leading cause of mortality and morbidity. Observation of the right atrial thrombi is a rare condition, which usually accompanies to massive PTE. Urgent treatment strategies for rapid thrombus removal are mandatory in patients presenting with acute massive PTE. In this paper, we present a patient admitting with acute massive PTE to our emergency department, in whom concomitant right atrial thrombus was successfully treated with reteplase.

Keywords: Acute pulmonary thromboembolism, reteplase, right atrial thrombi

\section{INTRODUCTION}

Pulmonary thromboembolism (PTE) is the most important emergencies in cardiovascular system with high rate of mortality without appropriate treatment. ${ }^{[1]}$ The diagnosis of PTE is difficult, and it may be overlooked because it does not emerge as of a specific clinical condition. Furthermore, in recent years, advances in diagnostic methods have also increased the frequency of diagnosis of PTE. The mortality rate in patients with PTE who cannot be diagnosed reaches $30 \%$; this rate may be reduced to $3 \%$ when diagnosed and treated appropriately. ${ }^{[2]}$ In the majority of cases, the source of thrombus is in the deep veins of the lower extremities, especially the common femoral, superficial, femoral, and popliteal pelvic veins.

\section{Case Report}

A 77-year-old woman was admitted to the emergency department with complaints of acute severe dyspnea and cyanosis. She reported that her complaints had begun 3 days ago. Before this event, she walked a long distance and done strenuous exercise. In her medical history, she had asthma. On admission, she was tachycardic (152 bpm), hypotensive $(85 / 52 \mathrm{mmHg})$, and tachypneic $\left(36 \mathrm{~min}^{-1}\right)$. Her oxygen saturation was $88 \%$ with oxygen mask. On physical examination, she had right ventricular $\mathrm{S}_{3}, 2 / 6$ systolic murmur on tricuspid area, and bilateral severe crackles in both lungs.

\begin{tabular}{|l|l|}
\hline \multicolumn{2}{|c|}{ Access this article online } \\
\hline Quick Response Code: & Website: \\
& \\
&
\end{tabular}

Her extremities were cyanotic. On electrocardiogram, tachycardia, atrial flutter, and right axis deviation were detected. Right ventricular dilation $(46 \mathrm{~mm})$ and severe hypokinesis of the right ventricle lateral wall were observed on transthoracic echocardiography (TTE). A highly erratic, $44 \mathrm{~cm} \times 19 \mathrm{~mm}$-sized worm-like mass appearance, originating from vena cava inferior and freely floating in the right atrium, consistent with "Thrombus in Transit" (ThIT) was detected on TTE [Figure 1]. Furthermore, her pulmonary artery pressure was measured $75 \mathrm{mmHg}$. The patient was diagnosed as acute massive pulmonary emboli. Her blood sample analysis showed anemia and thrombocytopenia (hemoglobin: $10.8 \mathrm{~g} \backslash \mathrm{dl}$ and platelet: 1 04.000). Since she had massive pulmonary emboli with cardiogenic shock, we immediately decided to initiate thrombolytic and intravenous anticoagulant therapy. Reteplase (10 IU bolus dose followed by a 10 IU bolus $30 \mathrm{~min}$ after) and unfractionated heparin were given. Two hours after thrombolytic therapy, her blood pressure turned to normal ranges and her oxygen saturation was raised to $93 \%$. Control TTE was performed the day after thrombolytic therapy, which revealed smaller right ventricular size $(39 \mathrm{~mm})$ and

Address for correspondence: Dr. Muhammet Bugra Karaaslan, Department of Cardiology, Faculty of Medicine, Cukurova University, 01000, Balcali, Saricam, Adana, Turkey. E-mail: bgkaraaslan@gmail.com

This is an open access journal, and articles are distributed under the terms of the Creative Commons Attribution-NonCommercial-ShareAlike 4.0 License, which allows others to remix, tweak, and build upon the work non-commercially, as long as appropriate credit is given and the new creations are licensed under the identical terms.

For reprints contact: reprints@medknow.com

How to cite this article: Karaaslan MB, Celik AI, Cagliyan CE, Demir M. Thrombus in transit causing acute massive pulmonary emboli treated successfully with reteplase administration. Int J Cardiovasc Acad 2018;4:35-6. 

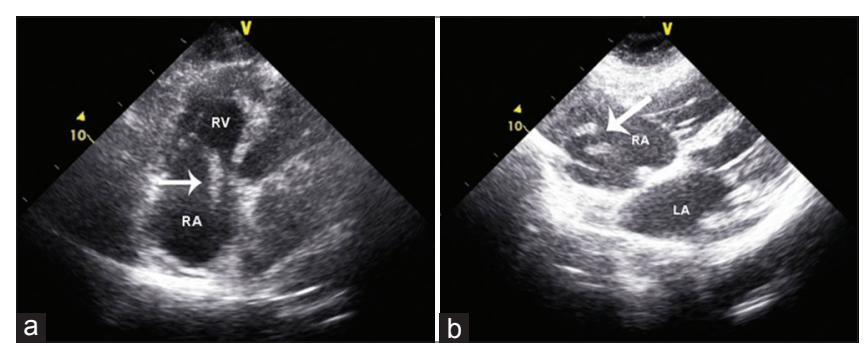

Figure 1: Apical four-chamber (a) and subcostal (b) views demonstrating highly erratic thrombus (white arrow) freely floating in the right atrium and protruding into the right ventricle. RA: Right atrium, RV: Right ventricle, LA: Left ventricle

lower pulmonary artery pressure $(48 \mathrm{mmHg})$ with no visible thrombus appearance [Figure 2]. Oral anticoagulant therapy with warfarin was started on the $3^{\text {rd }}$ day of her hospitalization. She was discharged on the $8^{\text {th }}$ day of her admission.

\section{Discussion}

Acute PTE usually occurs from deep venous thrombosis, and these thrombi migrate to the lungs through vena cava inferior and right atrium. Entrapment of thrombi in the right heart, so-called "thrombus in transit" (ThIT), is a rare finding, which is observed in only $4 \%$ of patients admitting with acute PTE. Patients presenting with ThIT in their right chambers are usually much more hemodynamically compromised than patients without ThIT. ${ }^{[3]}$ Observation of ThIT directly confirms acute PTE diagnosis, and no other imaging modality is required in the early phase for determination of management strategy. Administration of intravenous heparin alone or rapid elimination of thrombus is possible treatment choice in patients with ThIT-complicated acute PTE. ${ }^{[4]}$ On the other hand, 90-day mortality rates are significantly higher in patients treated with heparin alone; so, choosing a management strategy for rapid elimination of ThIT is highly reliable. ${ }^{[3]}$

Catheter-based extraction, surgical removal, and thrombolytic therapy are possible choices for rapid elimination of ThIT. Since most of the patients are hemodynamically unstable, administration of thrombolytic therapy seems easier and safer. On the other hand, disconnection of the thrombi from the entrapment area before complete lysis of it may theoretically lead to massive re-emboli. Continuous and slow infusion of thrombolytic agents may be preferable for getting over of this possible complication. There are case reports showing successful lysis of ThIT with streptokinase ${ }^{[5]}$ and tissue plasminogen activator ${ }^{[6]}$ Both agents are infused continuously in a longer period when compared to reteplase. Reteplase is approved for the treatment of acute coronary syndromes, but it has also been evaluated in individuals with acute PTE. ${ }^{[7]}$ Reteplase is the first clinically available modified tissue plasminogen activator produced by recombinant DNA technology. Reteplase preferentially activates plasminogen on the clot surface and is classified as fibrin specific. The fibrin-specific agents have longer half-lives (e.g., 11-19 min), which allow bolus administration. The recommended dose of
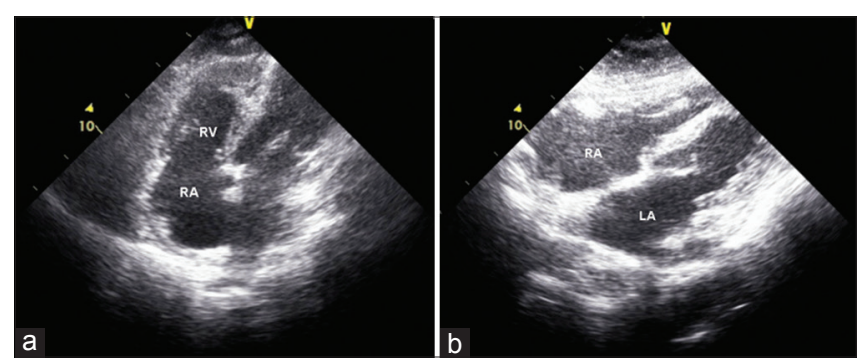

Figure 2: Apical four-chamber (a) and subcostal (b) view of the same patient after reteplase administration. No visible thrombus is seen and the right heart chambers are smaller. RA: Right atrium, RV: Right ventricle, LA: Left ventricle

reteplase is $10 \mathrm{U}$ followed by a further $10 \mathrm{U}$ after $30 \mathrm{~min}$. Each injection must be given over a period of no longer than $2 \mathrm{~min} .^{[8]}$ Reteplase also alleviates the risk of allergic reactions associated with the first-generation thrombolytics. Our case report is demonstrating successful thrombolysis of ThIT with reteplase in a patient admitting with acute massive PTE.

\section{Declaration of patient consent}

The authors certify that they have obtained all appropriate patient consent forms. In the form the patient(s) has/have given his/her/their consent for his/her/their images and other clinical information to be reported in the journal. The patients understand that their names and initials will not be published and due efforts will be made to conceal their identity, but anonymity cannot be guaranteed.

\section{Financial support and sponsorship \\ Nil.}

\section{Conflicts of interest}

There are no conflicts of interest.

\section{RefEREnCES}

1. Guidelines on the Diagnosis and Management of Acute Pulmonary Embolism. Task force on pulmonary embolism, European society of cardiology. Eur Heart J 2014;35:3033-80.

2. Yilmaz Z, Ercan G, Recep D. Affecting factors on early mortality in elderly patients diagnosed with pulmonary embolism in emergency department. Turk J Geriatr 2015;18:97-103.

3. Torbicki A, Galié N, Covezzoli A, Rossi E, De Rosa M, Goldhaber SZ, et al. Right heart thrombi in pulmonary embolism: Results from the international cooperative pulmonary embolism registry. J Am Coll Cardiol 2003;41:2245-51.

4. Mollazadeh R, Ostovan MA, Abdi Ardekani AR. Right cardiac thrombus in transit among patients with pulmonary thromboemboli. Clin Cardiol 2009;32:E27-31

5. Tekin K, Cağlıyan ÇE, Karaarslan O, Uysal OK, Özkan B, Çaylı M, et al. Witnessing a rare event: Thrombus in transit after coronary angiography. Anadolu Kardiyol Derg 2011;11:E22.

6. Ruiz-Bailén M, López-Caler C, Castillo-Rivera A, Rucabado-Aguilar L, Ramos Cuadra JA, Lara Toral J, et al. Giant right atrial thrombi treated with thrombolysis. Can J Cardiol 2008;24:312-4.

7. Meyer G, Vicaut E, Danays $\mathrm{T}$, et al. Fibrinolysis for patients with intermediate-risk pulmonary embolism. N Engl J Med 2014;370:1402-11.

8. Simpson D, Siddiqui MA, Scott LJ, Hilleman DE. Reteplase: A review of its use in the management of thrombotic occlusive disorders. Am J Cardiovasc Drugs 2006;6:265-85. 